\title{
The Effect of Body Mass Index on Physical Activity Level in Children between 10- 11 Years of Age
}

\author{
Gökmen Kilincarslan' \\ 'Bingol University, School of Physical Education and Sports, Bingol, Turkey. \\ Email: gkilincarslan@bingol.edu.tr
}

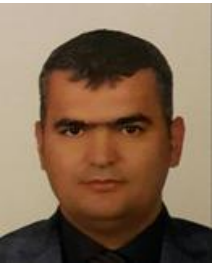

\begin{abstract}
The aim of this study was to investigate the effect of body mass index on physical activity (PA) level in children between 10-11 years of age. This research is an experimental study. While the universe of the research is composed of children studying in primary schools in Ankara province in 2017-2018 education and academic year, the sample is composed of students studying and teaching in Gazi Primary School in Yenimahalle district. The study included 271 students between the ages of 10 and 11 who voluntarily participated. The necessary permissions were obtained from school principals and student parents before the investigation. This research were taken weight $(\mathrm{kg})$, height $(\mathrm{m})$, PA level (pedometer) and BMI $\left(\mathrm{kg} /\right.$ height $\left.^{2}\right)$ measurements. SPSS 23 package program was used in the analysis of the obtained data. The mean age of children was $10,57 \pm 0,49$, mean height was $1,42 \pm 8,45$ and body weight was $38,33 \pm 10,91$. BMI was $17.64 \pm 3.07$ in 10 age group and $19.43 \pm 3.94$ in 11 age group. The level of PA was determined as $12288 \pm 1687$ for 10 years and $11328 \pm 1721$ for 11 years. There was a significant difference between the two groups $(\mathrm{p}<0.001)$. There was found to be negatively correlation with PA $(r=-0,269) \mathrm{p}<0.001$, whereas a significant correlation was found between BMI level $(r=0,240) p<0,001$. A significant correlation was found between BMI and PA level $(\mathrm{r}-0.817) \mathrm{p}<0.001$. As a result, it can be said that the body mass indexes of children between 10-11 years of age are in good level and their PA levels are generally active.
\end{abstract}

Keywords: BMI, Physical activity, Sedantery, Pedometer, Fitness, Children.

Citation | Gökmen Kilincarslan (2019). The Effect of Body Mass Index on Physical Activity Level in Children between 10-11 Years of Age. Asian Journal of Education and Training, 5(1): 193-197. History:

Received: 28 November 2018

Revised: 31 December 2018

Accepted: 1 February 2019

Published: 5 March 2019

Licensed: This work is licensed under a Creative Commons

Attribution 3.0 License (co)

Publisher: Asian Online Journal Publishing Group
Funding: This study received no specific financial support.

Competing Interests: The author declares that there are no conflicts of interests regarding the publication of this paper.

Transparency: The author confirms that the manuscript is an honest, accurate, and transparent account of the study was reported; that no vital features of the study have been omitted; and that any discrepancies from the study as planned have been explained.

Ethical: This study follows all ethical practices during writing.

\section{Contents}

1. Introduction

2. Methods 


\section{Introduction}

PA is associated with numerous immediate and long-lasting health benefits in children (Loprinzi et al., 2012) and an increased amount of physical activity generally increases the benefits (Klakk et al., 2013). PA is energy expenditure as a result of the body's movement through the skeletal muscles. Any PA requires energy expenditure. PA can be varied in different ways according to the characteristics of the training (aerobic, anaerobic or static, dynamic, etc.) PA is perceived synonymous with the word "sport" in the majority of society. However, physical activity is defined as activities that take place in daily life using muscles and joints with energy expenditure, increase heart and respiratory rate and result in fatigue at different intensity. In this context, as well as sports activities, exercise, games and various activities during the day are considered physical activity (Kutlu and Civi, 2013). Current recommendations on physical activity for children endorsed by the European Commission and the World Health Organization are for a minimum 60 minutes of daily moderate to vigorous physical activity (World Health Organization, 2010; Demirtas et al., 2017).

The reported proportion of children actually achieving the recommendation varies across studies, partly due to dissimilar definitions of moderate to vigorous physical activity (Guinhouya et al., 2013). Childhood is a period in which growth and development is fast. In this period, the intake of nutritional elements increasing the need is an important factor in preventing chronic diseases during adulthood. Healthy eating and lifestyle habits are shaped during childhood and become permanent. These habits are necessary for the protection and development of health. Being physically inactive, consuming "fast food" type foods frequently, spending a long time on television and computer, and consuming high calorie foods during these periods are the most important factors that affect being overweight and fat in children. Regular and balanced eating habits and regular physical activity are the most important factors for maintaining and improving health. Shaping healthy life habits in childhood can be achieved by education starting with childhood (Kutlu and Civi, 2013). Differences in neighbourhood characteristics could be another reason for the variety of physical activity levels in children. Positive effects of environmental factors in the neighbourhood, for example recreational facilities and parks, have been indicated for both physical activity levels and general health among children (Roemmich et al., 2006).

A recent review concluded significant positive associations between access, density and proximity to parks and objectively measured physical activity among children in four out of eight studies included, whereas no significant associations were seen in the other four studies (Ding et al., 2011). A lifestyle that includes physical activity plays an important role in disability and mortality in daily life. The fact that regular physical activity can prevent or delay different chronic diseases is well understood today (Pitta et al., 2006). Socioeconomic factors have been associated with physical activity among children, albeit with conflicting results (Singh et al., 2008) probably partly due to dissimilarities in the factors measured (e.g. income or education). Also seasonal factors may explain some of the differences (Rich et al., 2012). This factor could be especially important in a Scandinavian context with large seasonal variations in weather conditions, temperature and hours of daylight (Hjorth et al., 2013). Characteristics of the neighbourhood environment of children are likely to differ between countries and contexts. A majority of previous research that has found a relation between neighbourhood resources and physical activity in children has been performed in North America, while studies reflecting north European contexts are scarce (Davison and Lawson, 2006). In addition, lack of physical activity leads to obesity (Simşek, 2005).

Obesity is a disorder of energy metabolism resulting from excessive fat storage in the body, which can cause physical and mental problems. Taking more energy than consumed is the most important cause of obesity (Donohoue, 2004). The regulation of adipose tissues in the body and the etiology of obesity are multi-factor and are influenced by genetic structure, environmental warnings and developmental phenomena (Popkin, 2001). Changes in eating and activity habits cause obesity to be seen more frequently. Especially in genetically predisposed children, obesity is known to be caused by environmental factors (Donohoue, 2004). It is shown in a variety of studies in which the child's nutritional intake is shaped by the eating habits during the infancy period, the parents ' nutritional properties and the family environment may cause obesity (Birch and Fisher, 1998). On the other hand, obesity and being overweight are closely related to sedentary lifestyle and lack of physical activity (MartinezGonzalez et al., 2001).

The aim of this study was to investigate the effect of body mass index on physical activity level in children.

\section{Methods}

\subsection{Participants}

This research is an experimental study. While the universe of the research is composed of children studying in primary schools in Ankara province in 2017-2018 education and academic year, the sample is composed of students studying and teaching in Gazi Primary School in Yenimahalle district. The study included 271 students between the ages of 10 and 11 who voluntarily participated. The necessary permissions were obtained from school principals and student parents before the investigation.

\subsection{Height (cm) and Weight (kg) Measurements}

Height was measured to the nearest $0.1 \mathrm{~cm}$ by using a stadiometer. Weight was measured to the nearest $0,1 \mathrm{~kg}$ on an electronic scale (Seca Corp, Birmingham, United Kingdom).

\subsection{Measurement of Physical Activity Level}

Physical activity levels were measured on 5 weekdays and 2 weekend day using Kenz Lifecorder pedometer. Pedometers were placed on the hip and they were checked against any problems by taking a few steps before the measurements. They were made to wear these pedometers after getting up and kept them until going to bed. Daily step standards graphics were developed for youth by Tudor-Locke et al. (2008). 
Table-1. Physical Activity Levels Classification.

\begin{tabular}{l|c|c|c|c}
\hline Sedentary Lifestyle & Low Active & Somewhat Active & Active & Very Active \\
\hline$<5000$ & $5000-7499$ & $7500-9999$ & $10000-12499$ & $>12500$ \\
\hline Source: Tudor-Locke et al. (2008).
\end{tabular}

2.4. BMI (Body Mass Index)

BMI was calculated as body mass in kilograms divided by height in meters squared $(\mathrm{kg} / \mathrm{m} 2)$. Body Composition was evaluated by using Body Mass Index criteria which were designed by Welk et al. (2000).

Table-2. Body Mass Index Classification.

\begin{tabular}{|c|c|c|c|c|c|c|}
\hline Gender & Too low & Borderline & Good Fitness & Overweight & Obesity & \\
\hline Male & 12 or less & $13-16$ & $17-25$ & $26-30$ & $30+$ & \multirow{2}{*}{$\begin{array}{l}\text { BMI } \\
\left(\text { weight/height }{ }^{2}\right)\end{array}$} \\
\hline Famale & 12 or less & $13-16$ & $17-25$ & $26-30$ & $30+$ & \\
\hline
\end{tabular}

Source: Welk et al. (2000).

\subsection{Statistical Analysis}

SPSS 23 package program was used in the analysis of the obtained data. The mean and standard deviation values of the subjects ' age, height and body weight were calculated. Independent t test was applied according to age variables. Also a correlation analysis was performed to determine the relationship between physical activity and BMI.

\section{Findings}

Table-3. Mean age, height and body weight of children.

\begin{tabular}{c|c|c|c}
\hline Variables & $\mathbf{N}$ & Mean & Standard Deviation \\
\hline Age & 271 & 10,57 &, 496 \\
\hline Height & 271 & 142,30 & 8,454 \\
\hline Weight & 271 & 38,33 & 10,913 \\
\hline
\end{tabular}

According to Table 3, mean age of children was $10,57 \pm 0,49$, mean height was $1,42 \pm 8,45$ and body weight was $38,33 \pm 10,91$.

Table-4. Comparison of BMI and physical activity level by age.

\begin{tabular}{|c|c|c|c|c|c|c|}
\hline Variables & Age & $\mathbf{N}$ & Mean & Standard Deviation & $\mathrm{t}$ & $\mathbf{p}$ \\
\hline \multirow{2}{*}{ BMI } & 10 & 116 & 17,64 & 3,07 & \multirow{2}{*}{$-4,046$} & \multirow{2}{*}{$<0,00$} \\
\hline & 11 & 155 & 19,43 & 3,94 & & \\
\hline \multirow{2}{*}{ Physical Activity Level } & 10 & 116 & 12288,05 & 1687,77 & \multirow{2}{*}{4,578} & \multirow{2}{*}{$<0, \mathrm{OC}$} \\
\hline & 11 & 155 & 11328,44 & 1721,98 & & \\
\hline
\end{tabular}

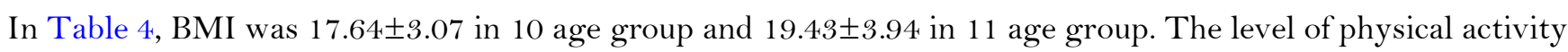
was determined as $12288 \pm 1687$ for 10 years and $11328 \pm 1721$ for 11 years. There was a significant difference between the two groups $(\mathrm{p}<0.01)$.

Table-5. Relationship between age, BMI and physical activity levels of children.

\begin{tabular}{c|c|c|c}
\hline Variables & Methods & Age & Physical Activity Level \\
\hline \multirow{2}{*}{ Physical Activity Level } & Pearson Correlation &,$- 269^{* *}$ & \\
\cline { 2 - 4 } & Sig. (2-tailed) &, 000 & \multirow{2}{*}{,, $817^{* *}$} \\
\hline \multirow{2}{*}{ BMI } & Pearson Correlation &, $240^{* *}$ &, 000 \\
\cline { 2 - 4 } & Sig. (2-tailed) &, 000 & \\
\hline
\end{tabular}

According to Table 5,there was found to be negatively correlation with physical activity $(\mathrm{r}=-0,269) \mathrm{p}<0.01$, whereas a significant correlation was found between BMI level $(r=0,240) p<0,001$. A significant correlation was found between BMI and physical activity level $(\mathrm{r}-0.817) \mathrm{p}<0.01$.

\section{Conclusion and Discussion}

In our study, a significant difference was found at the level of $\mathrm{p}<0.001$ in physical activity level and BMI values according to age. According to our research, as the level of physical activity increases, BMI is decreasing. As the age increases, the level of physical activity decreases and the BMI increases. In our study, the mean age of the children was $10.57 \pm 0.49$, the mean height was $1.42 \pm 8.45$ and the body weight was $38.33 \pm 10.91$. In our study, BMI was determined as $17.64 \pm 3.07$ for children aged 10 years and $19.43 \pm 3.94$ for 11 years. Physical activity level was determined as $12288 \pm 1687$ for 10 years and $11328 \pm 1721$ for 11 years. A significant difference was found between the BMI and physical activity level at the level of $\mathrm{p}<0.01$ according to age variable. A negatively significant correlation was found between age and physical activity $(r=-0,269)$ at a $p<0.01$ level while positively significant correlation with BMI $(r=0,240) p<0,01$. A negatively significant correlation was found between BMI and physical activity level $(\mathrm{r}-0,817) \mathrm{p}<0,01$.

Belton et al. (2010) has been determined that the height values of children between 6-9 years of age are $1.31 \mathrm{~m}$., body weight $29.2 \mathrm{~kg}$ and BMI $17 \mathrm{~kg} / \mathrm{m}^{2}$. As Duncan et al. (2007) the height values of children between 8-11 years 
of age are $1.39 \mathrm{~m}$., body weight 33,3 $\mathrm{kg}$ and BMI $17,5 \mathrm{~kg} / \mathrm{m}^{2}$. As Kolle et al. (2009) the height values of children in 9 years of age are $1.39 \mathrm{~m}$., body weight $33,9 \mathrm{~kg}$ and BMI $17,2 \mathrm{~kg} / \mathrm{m}^{2}$. As Deforche et al. (2009) BMI of children between 6-10 years of age are $15,7 \mathrm{~kg} / \mathrm{m}^{2}$. As Gorely et al. (2009) BMI of children between 7-11 years of age are $17,5 \mathrm{~kg} / \mathrm{m}^{2}$. As Ridgers et al. (2007) the height values of children's years of age are $1.33 \mathrm{~m}$., body weight $31,9 \mathrm{~kg}$ and BMI $17,8 \mathrm{~kg} / \mathrm{m}^{2}$. According to Stein et al. (2007) the height, body weight and BMI values of children between 10-12 years old have increased with the age. In the study of Komata (2002) conducted to 10 years old children with 6 months intervals it is indicated that the height and the body weight of boys have increased in terms of the age.

Le-Masurier et al. (2003) indicated that there was a negative correlation between BMI and body weight and physical activity levels, and that physical activity steps and levels from childhood to old age showed a steady decline.

According to Belton $e t$ al. (2010) the physical activity levels of 6-9 boys were defined as 16821 steps, Duncan $e t$ al. (2007) stated the physical activity levels of 8-11 year-olds as 12263 steps. Duncan et al. (2006) children have a level of 14124 daily steps. Gorely stated the physical activity level steps of children as 9789 per day. Raustorp and Ludvigsson (2007) indicated that children had a daily step level of 15991-16273. Cox et al. (2006) stated the average daily step levels of men as 15606, Craig et al. (2010) as 12259 steps. Deforche et al. (2009) indicated the physical activity levels of boys between 6-10 years of age as gold.

Tudor-Locke and Bassett (2004) indicated in the study named "how many steps are enough?" that 5000 steps and below sedentary, 5000-7459 steps are low active group, 7500-9999 steps are a little active, 10000-12499 steps are active, and 12500 steps and above are high active. Locke stated that children taking physical activity steps between 12000-15000 daily have a healthier and more positive BMI level, as well as children have an average of 8000-12000 steps, and men have an average of 13000 daily steps.

In the study of Tudor-Locke and Bassett (2004) they indicated that 5000 steps and below have really bad life quality, between 5000 and 7499 have sedentary, between 7500 and 9999 have low life quality, 1000 steps and above have good life quality.

According to our research; for the protection or enhancement of physical activity; it is recommended to make physical activity more fun and to create activities appropriate for age groups. The duration of use of television, computer and smartphone should be reduced, and regular sleep times should be encouraged. Foods sold in school canteens should be inspected and banned food such as cola and chips should be encouraged. Increasing the number of physical activity areas in playgrounds in schools and after school will play an important role in children's physical activity habits.

As a result, it can be said that the body mass indexes of children between 10-11 years of age are in good level and their physical activity levels are generally active.

\section{References}

Belton, S., P. Brady, S. Meegan and C. Woods, 2010. Pedometer step count and BMI of Irish primary school children aged 6-9 years. Preventive Medicine, 50(4): 189-192.Available at: https://doi.org/10.1016/j.ypmed.2010.01.009.

Birch, L.L. and J.O. Fisher, 1998. Development of eating behaviors among children and adolescents. Pediatrics, 101(Supplement 2): 539-549.

Cox, M., G. Schofield, N. Greasley and G.S. Kolt, 2006. Pedometer steps in primary school-aged children: A comparison of school-based and out-of-school activity. Journal of Science and Medicine in Sport, 9(1-2): 91-97.Available at: https://doi.org/10.1016/j.jsams.2005.11.003.

Craig, C.L., C. Cameron, J.M. Griffiths and C. Tudor-Locke, 2010. Descriptive epidemiology of youth pedometer-determined physical activity: CANPLAY. Medicine \& Science in Sports \& Exercise, 42(9): 1639-1643.Available at: https://doi.org/10.1249/mss.obo13e3181d58a92.

Davison, K.K. and C.T. Lawson, 2006. Do attributes in the physical environment influence children's physical activity? A review of the literature. International Journal of Behavioral Nutrition and Physical Activity, 3(19): 5868-5863.

Deforche, B., I. De Bourdeaudhuij, E. D'hondt and G. Cardon, 2009. Objectively measured physical activity, physical activity related personality and body mass index in 6-to 10-yr-old children: A cross-sectional study. International Journal of Behavioral Nutrition and Physical Activity, 6(1): 25.Available at: https://doi.org/10.1 186/1479-5868-6-25.

Demirtas, Ş., C. Güngör and R.N. Demirtas, 2017. Healthy aging and physical activity: Individual, psychosocial and environmental characteristics. Osmangazi Medical Journal, 39(1): 100-108.

Ding, D., J.F. Sallis, J. Kerr, S. Lee and D.E. Rosenberg, 2011. Neighborhood environment and physical activity among youth: A review. American Journal of Preventive Medicine, 41(4): 442-455.Available at: https://doi.org/10.1016/j.amepre.201 1.06.036.

Donohoue, P.A., 2004. Obesity. In: Nelson textbook of pediatrics. Eds: Behrman, R.E., Kliegman, R.M., Jenson, H.B., 17 th ed. Philadelphia: W.B. Saunders. pp: 173-177.

Duncan, J.S., G. Schofield and E.K. Duncan, 2006. Pedometer-determined physical activity and body composition in New Zealand children. Medicine and Science in Sports and Exercise, 38(8): 1402-1409.Available at: https://doi.org/10.1249/01.mss.0000227535.36046.97.

Duncan, M.J., Y. Al-Nakeeb, L. Woodfield and M. Lyons, 2007. Pedometer determined physical activity levels in primary school children from central England. Preventive Medicine, 44(5): 416-420.Available at: https://doi.org/10.1016/j.ypmed.2006.11.019.

Gorely, T., M.E. Nevill, J.G. Morris, D.J. Stensel and A. Nevill, 2009. Effect of a school-based intervention to promote healthy lifestyles in 7-11 year old children. International Journal of Behavioral Nutrition and Physical Activity, 6(1): 5.Available at: https://doi.org/10.1186/1479-5868-6-5.

Guinhouya, B., H. Samouda and C. De Beaufort, 2013. Level of physical activity among children and adolescents in Europe: A review of physical activity assessed objectively by accelerometry. Public Health, 127(4): 301-311.Available at: https://doi.org/10.1016/j.puhe.2013.01.020.

Hjorth, M.F., J.-P. Chaput, K. Michaelsen, A. Astrup, I. Tetens and A. Sjödin, 2013. Seasonal variation in objectively measured physical activity, sedentary time, cardio-respiratory fitness and sleep duration among 8-11 year-old Danish children: A repeated-measures study. BMC Public Health, 13(1): 808.Available at: https://doi.org/10.1186/1471-2458-13-808.

Klakk, H., L.B. Andersen and M. Heidemann, 2013. Six physical education lessons a week can reduce cardiovascular risk in school children aged 6-13 years: A longitudinal study. Scandinavian Journal of Public Health, 42(2): 128-136.Available at: https://doi.org/10.1177/1403494813505726.

Kolle, E., J. Steene-Johannessen, L.B. Andersen and S.A. Anderssen, 2009. Seasonal variation in objectively assessed physical activity among children and adolescents in Norway: A cross-sectional study. International Journal of Behavioral Nutrition and Physical Activity, 6(1): 36.Available at: https://doi.org/10.1186/1479-5868-6-36

Komata, R., 2002. Grip strength of elementary school children. The 44. Ishper-SD World Congress, Taipei, Taiwan, pp: $414-421$.

Kutlu, R. and S. Civi, 2013. Evaluation of eating habits, body perception and depression status of university students. Gulhane Medical Journal, 53(3): 196-202.Available at: https://doi.org/10.5455/gulhane.23380.

Le-Masurier, G.C., C.L. Sidman and C.B. Corbin, 2003. Accumulating 10,000 steps: Does this meet current physical activity guidelines? Research Quarterly for Exercise and Sport, 74(4): 389-394.Available at: https://doi.org/10.1080/02701367.2003.10609109. 
Loprinzi, P.D., B.J. Cardinal, K.L. Loprinzi and H. Lee, 2012. Benefits and environmental determinants of physical activity in children and adolescents. Obesity Facts, 5(4): 597-610.Available at: https://doi.org/10.1159/000342684.

Martinez-Gonzalez, M.A., J.J. Varo, J.L. Santos, J.D. Irala, M. Gibney, J. Kearney and J.A. Martinez, 2001. Prevalence of physical activity during leisure time in the European union.

Pitta, F., T. Troosters, V.S. Probst, M.A. Spruit, M. Decramer and R. Gosselink, 2006. Physical activity and hospitalization for exacerbation of COPD. Chest, 129(3): 536-544.Available at: https://doi.org/10.1378/chest.129.3.536.

Popkin, B.M., 2001. The nutrition transition and obesity in the developing world. The Journal of Nutrition, 131(3): 871S-873S.Available at: https://doi.org/10.1093/jn/131.3.871s.

Raustorp, A. and J. Ludvigsson, 2007. Secular trends of pedometer-determined physical activity in Swedish school children. Acta Paediatrica, 96(12): 1824-1828.Available at: https://doi.org/10.1111/j.1651-2227.2007.00525.x.

Rich, C., L.J. Griffiths and C. Dezateux, 2012. Seasonal variation in accelerometer-determined sedentary behaviour and physical activity in children: A review. The International Journal of Behavioral Nutrition and Physical Activity, 9(1): 49.Available at: https://doi.org/10.1186/1479-5868-9-49.

Ridgers, N.D., G. Stratton, S.J. Fairclough and J.W. Twisk, 2007. Long-term effects of a playground markings and physical structures on children's recess physical activity levels. Preventive Medicine, 44(5): 393-397.Available at: https://doi.org/10.1016/j.ypmed.2007.01.009.

Roemmich, J.N., L.H. Epstein, S. Raja, L. Yin, J. Robinson and D. Winiewicz, 2006. Association of access to parks and recreational facilities with the physical activity of young children. Preventive Medicine, 43(6): 437-441.Available at: https://doi.org/10.1016/j.ypmed.2006.07.007.

Simşek, F., 2005. Obesity prevalence in a primary school and a high school in Ankara. University Journal of Medical Faculty, 58(4): 163166.Available at: https://doi.org/10.1501/tipfak_0000000166.

Singh, G.K., M.D. Kogan, M. Siahpush and P.C. Van Dyck, 2008. Independent and joint effects of socioeconomic, behavioral, and neighborhood characteristics on physical inactivity and activity levels among US children and adolescents. Journal of Community Health, 33(4): 206-2 16.Available at: https://doi.org/10.1007/s 10900-008-9094-8.

Stein, C., L. Fisher, C. Berkey and G. Colditz, 2007. Adolescent physical activity and perceived competence: Does change in activity level impact self-perception? Journal of Adolescent Health, 4O(5): 462. e461-462. e468.Available at: https://doi.org/10.1016/j.jadohealth.2006.11.147.

Tudor-Locke, C. and D.R. Bassett, 2004. How many steps/day are enough? Sports Medicine, 34(1): 1-8.Available at: https://doi.org/10.2 165/00007256-200434010-00001.

Tudor-Locke, C., Y. Hatano, R.P. Pangrazi and M. Kang, 2008. Revisiting" how many steps are enough?". Medicine \& Science in Sports \& Exercise, 40(7): S537-S543.Available at: https://doi.org/10.1249/mss.ob013e31817c7133.

Welk, G.J., C.B. Corbin and D. Dale, 2000. Measurement issues in the assessment of physical activity in children. Research Quarterly for Exercise and Sport, 71(sup2): 59-73.Available at: https://doi.org/10.1080/02701367.2000.11082788.

World Health Organization, 2010. Global recommendations on physical activity for health. Geneva: WHO. 